University of Nebraska - Lincoln

DigitalCommons@University of Nebraska - Lincoln

2000

\title{
Patterns of Annual Seed Production by Northern Hemisphere Trees: A Global Perspective
}

Walter D. Koenig

University of California - Berkeley

Johannes M.H. Knops

University of Nebraska-Lincoln, jknops@unl.edu

Follow this and additional works at: https://digitalcommons.unl.edu/bioscifacpub

Part of the Life Sciences Commons

Koenig, Walter D. and Knops, Johannes M.H., "Patterns of Annual Seed Production by Northern Hemisphere Trees: A Global Perspective" (2000). Faculty Publications in the Biological Sciences. 129. https://digitalcommons.unl.edu/bioscifacpub/129

This Article is brought to you for free and open access by the Papers in the Biological Sciences at DigitalCommons@University of Nebraska - Lincoln. It has been accepted for inclusion in Faculty Publications in the Biological Sciences by an authorized administrator of DigitalCommons@University of Nebraska - Lincoln. 


\title{
Patterns of Annual Seed Production by Northern Hemisphere Trees: A Global Perspective
}

\author{
Walter D. Koenigi, ${ }^{1, *}$ and Johannes M. H. Knops ${ }^{2}$
}

1. Hastings Reservation and Museum of Vertebrate Zoology, University of California, Berkeley, Carmel Valley, California 93924; 2. School of Biological Sciences, University of Nebraska, Lincoln, Nebraska 68588-0118

Submitted January 12, 1999; Accepted August 4, 1999

ABSTRACT: We tested whether annual seed production (masting or mast fruiting) in Northern Hemisphere trees is an evolved strategy or a consequence of resource tracking by comparing masting patterns with those of annual rainfall and mean summer temperatures, two environmental variables likely to correlate with available resources. There were generally significant negative autocorrelations between the seed crop in year $x$ and year $x+1$ (year $x+2$ in species of Quercus requiring $2 \mathrm{yr}$ to mature acorns), as expected if resources are depleted in mast years in part by switching resources from growth to reproduction. Spatial autocorrelation in annual seed production generally declined with distance but was statistically significant over large geographic areas. Variability in annual seed production was relatively high and inversely correlated with latitude and generally not bimodally distributed. Patterns of spatial autocorrelation in annual rainfall and summer temperatures are generally similar to those exhibited by annual seed production, and relative variability in annual rainfall is also inversely correlated with latitude. However, these environmental variables exhibit distinctly different patterns of temporal autocorrelation, are much less variable, and are more normally distributed than annual seed production. Combined with the inverse relationship between growth and reproduction previously documented, these results support the hypothesis that variability in annual seed production is an evolved strategy and that annual seed production is more or less normally distributed rather than an all-or-none phenomenon.

Keywords: masting, mast fruiting, resource tracking, seed production, spatial patterns.

Masting, or mast fruiting, is the intermittent production of large seed crops by a population of plants. Kelly (1994)

\footnotetext{
* E-mail: wicker@uclink4.berkeley.edu.
}

Am. Nat. 2000. Vol. 155, pp. 59-69. (C) 2000 by The University of Chicago. 0003-0147/2000/15501-0006\$03.00. All rights reserved. distinguished three levels of masting: "putative" masting, in which seed crops vary greatly but there is no evidence that anything more than tracking resources is involved; "normal" masting, in which individuals switch resources from vegetative growth or reserves to seed production in mast years but still produce at least some seeds in other years; and "strict" masting, in which annual seed output is either very large or nil and thus unambiguously bimodal. Although variable seed production is known or presumed for most Northern Hemisphere trees, few taxa have been studied in sufficient detail to determine the level of masting involved, nor have the general patterns of masting been investigated, with the recent exception of Herrera et al. (1998).

There are at least two reasons why such patterns are of general importance. First, they shed light on the question of whether masting is an evolved reproductive strategy or merely a direct response to annual environmental variability, also known as "resource matching" (Büsgen and Münch 1929). If the latter, then the putative masting pattern should mimic that of some key environmental variable, and no further evolutionary explanation is necessary. If the former, then the normal or "strict" masting patterns presumably confer a selective benefit and are an adaptation to some challenge in the environment. Various evolutionary hypotheses for the critical selective benefit have been proposed; the most common of which are predator satiation or economies of scale related to wind pollination (Silvertown 1980; Norton and Kelly 1988; Smith et al. 1990; Kelly 1994).

The patterns of seed production by forest trees are also of general relevance to ecosystems because of the importance of mast as a food resource to wildlife whose populations may be significantly altered depending on the seed crop (Bock and Lepthien 1976; Hannon et al. 1987). Indeed, recent work has demonstrated that seed production by oaks (genus Quercus) in eastern North America has cascading effects on communities extending from the mice and deer that feed directly on acorns down through the ticks that live on the mice and deer and the viruses that are spread by the ticks (Ostfeld et al. 1996; Jones et al. 
1998). Thus, understanding the patterns of mast production by forest trees is likely to be important in understanding the population variability of a wide range of wildlife inhabiting temperate and boreal forests worldwide.

Here, we examine patterns of annual seed production by populations of Northern Hemisphere trees with two primary goals. First, we test three predictions of the hypothesis that seed production involves more than resource matching, as defined above. However, none of these predictions are definitive because all three predicted patterns could be the result of resource tracking if environmental variability matches that of seed production. Thus, in addition, we compare the patterns of annual seed production with those of annual rainfall and mean summer temperatures to test the possibility that variable seed production patterns, although consistent with normal masting as defined above, are the result of the tracking of environmental variables that exhibit similar temporal and spatial variability.

In contrast to most previous analyses, we approach the phenomenon of masting not from the perspective of an individual population or species but rather at the level of genera and families of trees distributed over much of the Northern Hemisphere. The justification of this approach is that masting is a population phenomenon (Kelly 1994) that not only transcends individual behavior but may even cross species and generic boundaries over large geographic areas (Koenig and Knops 1998a). Thus, we examine the predictions of masting on a much larger scale, both taxonomically and geographically, than has been attempted previously. We test three predictions of normal/strict (hereafter "true") masting.

Prediction 1: Temporal Autocorrelation. True masting species are predicted to switch resources from available reserves into seed production to produce large seed crops, leading to a negative correlation between seed production in a particular year and in the subsequent year (Sork et al. 1993; Kelly 1994). Variation in seed production as a result of environmental tracking is not enhanced by resource switching.

Prediction 2: Spatial Autocorrelation. Annual seed production by true masting species should be synchronized with a widely uniform environmental cue so as to maximize synchrony between individuals (Norton and Kelly 1988). Variation in seed production as a result of environmental tracking should correlate strongly with resource availability, but the critical resource need not be uniform on a large geographic scale.

Prediction 3: Variability in Annual Seed Production. The frequency distribution of annual seed production in true masting species should be bimodal and the coefficient of variation should be large. For strict masting species, there should be few, if any, years of intermediate seed produc- tion: in most years the population should produce either very many or virtually no seeds. Consequently, distributions of annual seed production should be highly platykurtic (kurtosis < 0; Sokal and Rohlf 1981).

A fourth prediction of true masting is that there should be switching of resources between seed production and vegetative growth within years (Norton and Kelly 1988). This has been confirmed on a large geographic scale by Koenig and Knops (1998a).

Prediction 2 raises a general problem in distinguishing true masting from resource tracking: both hypotheses predict that seed production patterns should correlate with environmental factors. Consequently, we compare patterns of variability in annual seed production with two environmental variables that are likely to be those used as cues by forest trees: annual rainfall and mean temperature during the growing season. Both have been shown to correlate with annual seed production of various tree species (Norton and Kelly 1988; Sork et al. 1993; Woodward et al. 1994), and both are suspected to be widely uniform over large geographic areas (Norton and Kelly 1988). For example, annual rainfall and temperature during flowering in the spring are the most important environmental factors determining acorn crop size in several species of California oaks and also appear to be the variables that synchronize acorn production over distances of at least several hundred kilometers (Koenig et al. 1996). Similarly, work by Ashton et al. (1988) on fruit production in Far Eastern dipterocarps has demonstrated that temperature drops associated with El Niño-Southern Oscillation events apparently trigger synchronous flower induction over a large area of the Malaysian peninsula and beyond.

\section{Methods}

\section{Seed Production}

Data on annual seed production were obtained from the literature. Both standard publications and governmental reports were used as long as they provided at least $4 \mathrm{yr}$ of seed production data on some taxon of Northern Hemisphere trees. When data for multiple species or more than one site were provided, they were entered as additional data sets. In all, we compiled 443 sets of data from 72 different sources yielding a total of 5,182 $\mathrm{yr}$ of data $(\bar{X}=11.7 \mathrm{yr}$ per site). Ten genera in three families provided sufficient data for analysis, either individually or combined with other related taxa. Table 1 lists the taxa analyzed; a complete listing of the raw data and references are available from the authors on request and in the online edition of the American Naturalist. 
Table 1: Data used in the analysis of annual seed production patterns

\begin{tabular}{|c|c|c|c|}
\hline $\begin{array}{l}\text { Family and } \\
\text { common name }\end{array}$ & Major species & $\begin{array}{l}\text { Data sets } \\
\qquad(N)\end{array}$ & $\begin{array}{c}\text { Years of data } \\
(N)\end{array}$ \\
\hline Betulaceae: birch & Betula pubescens, B. verrucosa & 40 & 454 \\
\hline \multicolumn{4}{|l|}{ Fagaceae: } \\
\hline Beech & Fagus sylvatica & 26 & 318 \\
\hline Oak & $\begin{array}{l}\text { Quercus alba, Q. coccinea, Q. } \\
\text { robur, Q. rubra, Q. stel- } \\
\text { lata, Q. velutina }\end{array}$ & 80 & 716 \\
\hline \multicolumn{4}{|l|}{ Pinaceae: } \\
\hline Fir & $\begin{array}{l}\text { Abies amabilis, A. concolor, } \\
\text { A. lasiocarpa, A. procera, } \\
\text { A. siberica }\end{array}$ & 46 & 395 \\
\hline Larch & Larix occidentalis, L. sibirica & 17 & 149 \\
\hline Spruce & $\begin{array}{l}\text { Picea abies, } P \text {. engelmannii, } P \text {. } \\
\quad \text { glauca, } P \text {. mariana }\end{array}$ & 62 & 1,017 \\
\hline Pine & $\begin{array}{l}\text { Pinus albicaulis, } P \text {. contorta, } \\
\text { P. monticola, } P \text {. ponderosa, } \\
\text { P. sylvestris }\end{array}$ & 136 & 1,684 \\
\hline Douglas-fir & Pseudotseuga menziesii & 18 & 285 \\
\hline Cedar & Thuja occidentalis, T. plicata & 6 & 69 \\
\hline Hemlock & Tsuga mertensiana & 12 & 95 \\
\hline
\end{tabular}

These data were collected in a wide variety of ways, presenting a formidable barrier to comparisons across studies. For data sets that presented categorical data ( $n=85$ datasets), we ranked the categories in order of increasing crop size, giving the highest category a 10 , the lowest category a 0 , and making the difference between all intermediate categories equal. For example, if only three categories were used (i.e., good, fair, and poor), years when the crop was rated as good were given a 10; those in which the crop was rated as fair were given a 5; and those in which it was rated as poor were given a 0 . Categories were divided more finely, but still equally, if more than three categories were used. Thus, if six categories were reported (i.e., excellent, very good, good, fair, poor, very poor), ratings were assigned the values $10,8,6,4,2$, and 0 , respectively. Categorical data sets were used in the analyses of temporal and spatial autocorrelation but not in the analyses involving distributional attributes of individual data sets (coefficient of variation, skewness, and kurtosis) or bimodality.

Interval and ratio-level data, such as the visual counts or number of seeds falling in traps ( $n=291$ data sets), were used in all analyses. For examination of temporal and spatial autocorrelation, raw untransformed values were used; however, analyses were also performed using logtransformed values $(\log [x+1]$, frequently applied to seed production data; Koenig et al. 1994) with similar results.
Distributional attributes and bimodality results are presented using both raw and log-transformed values.

\section{Environmental Variables}

Monthly rainfall and mean temperature were downloaded from the National Oceanic and Atmospheric Administration web site (ftp://ftp.ncdc.noaa.gov/pub/data/ghcn). In order to conform to the seed production data, we did not use data before 1900 in assessing spatial or temporal autocorrelation and only used sites between $35^{\circ}$ and $70^{\circ} \mathrm{N}$ latitude. Annual rainfall for year $x$ was calculated by summing monthly values from September in year $x-1$ through August of year $x$. For mean temperature of year $x$, we averaged values for April through August of year $x$. These months were chosen to represent water availability (in the case of rainfall) and the growing season (in the case of mean temperature) for trees during year $x$ over the large geographic area covered by the Northern Hemisphere. For the analyses of temporal and spatial autocorrelation, long-term trends were eliminated by replacing values with residuals from a regression of the environmental variable on year (Koenig 1999).

Coefficients of variation are not meaningful unless all observations are inherently positive (Wallis and Roberts 1956). Thus, only rainfall was compared to seed production data in the analyses of relative variation. Skewness 
and kurtosis were calculated for both rainfall and mean temperature data sets. In order to ensure comparability with the seed production data, distributional attributes were calculated based on both raw and log-transformed values. In all, rainfall data were available from 4,701 sites $(\bar{X}=56.4$ yr per site $)$ and mean temperature from 3,225 sites $(\bar{X}=63.8$ yr per site).

\section{Analyses}

Temporal Autocorrelation. We calculated correlograms consisting of the ordered autocorrelation functions (Royama 1992) for time lags of $1-5 \mathrm{yr}$ for each data set. Six data points (pairs of years) were required for each analysis. Autocorrelations for each lag period were averaged for all data sets meeting the minimum sample size. Confidence limits of the autocorrelation coefficients were determined by randomization tests. An $\alpha$ level of $<0.05$, adjusted by the sequential Bonferroni technique, was considered significant. Analyses were performed on annual rainfall, mean temperature, and six tree genera with sufficient sample sizes. Data for oaks (genus Quercus) were further divided according to whether species require 1 or $2 \mathrm{yr}$ to mature acorns; major "1-yr species" include Quercus alba, Quercus robur, and Quercus stellata, while major "2-yr species" include Quercus coccinea, Quercus rubra, and Quercus velutina.

Spatial Autocorrelation. For the two environmental variables and each set of seed production data, we calculated Pearson correlation coefficients $(r)$ for all pairwise combinations of sites for which data from at least $4 \mathrm{yr}$ were in common. For example, if data set A presented data between 1980 and 1989 while data set B went from 1984 to 1992 , the correlation between the acorn production values of the two data sets for the 6 yr 1984 through 1989 was calculated along with the distance between the two sites. This yielded two matrices: one of the distance between sites and the other of the correlation coefficient between the seed crops measured over the years held in common at the two sites.

Three sets of analyses investigated patterns of spatial autocorrelation in these data. First, we performed Mantel tests (Fortin and Gurevitch 1993) to examine the overall relationship between distance and the correlation coefficient between pairs of sites. The Mantel test consists of comparing the correlation coefficients (normalized Mantel $r$ ) obtained from the observed data with correlation coefficients obtained following randomization trials in which the values of one of the matrices were shuffled at random. We performed 1,000 trials (100 for the environmental variables) for each test; $P$ values are based on the proportion of trials in which the randomized data yielded $r$ values greater than (or less than) the observed value, again adjusted using the sequential Bonferroni technique within data sets (Legendre and Fortin 1989).

Second, we calculated spatial Mantel correlograms (Oden 1984; Oden and Sokal 1986; Legendre and Fortin 1989) for each data set. This involved calculating the Pearson correlation coefficients between the standardized annual values of seed crops for all years that were measured in common between all pairs of sites that had at least $4 \mathrm{yr}$ in common. Each set of correlation coefficients was then divided into seven distance categories depending on whether the great-circle distance between the sites being compared was <10, 10-99, 100-499, 500-999, $1,000-2,499,2,500-4,999$, or $>5,000 \mathrm{~km}$. As before, significance was tested by randomization with values adjusted using sequential Bonferroni corrections.

Mantel correlograms reveal spatial structure relative to the overall data set (Koenig 1999). Thus, we also calculated "modified correlograms" using the procedure of Koenig and Knops (1998b). These are similar to Mantel correlograms except that mean $r$ values are tested as to whether they are significantly $>0$ by randomization. Significance was determined for data yielding at least 50 pairwise comparisons.

The modified correlogram procedure provides a statistical test that measures whether among-years acorn production at sites a given distance apart tends to be synchronous, defined as having mean $r$ values $>0$. However, this definition of synchrony is much less strict than often envisioned; sites may be statistically synchronous according to the test even though mean $r$ values are small.

Distribution of Annual Seed Production Values. We calculated the percentage of coefficient of variation $(\mathrm{CV}=\mathrm{SD} \times 100 / \bar{X})$, skewness, and kurtosis using the raw and log-transformed data sets that provided interval or ratio-level data and at least $6 \mathrm{yr}$ of information. The CVs of log-transformed seed production declined slightly with sample size $\left(r_{\mathrm{s}}=-0.13, n=291, P=.024\right)$. Thus, tests comparing CVs were performed both with nonparametric tests and with a general linear model in which sample size (number of years of data) was included as an independent variable. Results were in all cases similar, and thus only the nonparametric tests are reported here.

To test for bimodality, we first tested individual data sets for normality using a Kolmogorov-Smirnov onesample test. Only data sets providing interval or ratiolevel data with at least $6 \mathrm{yr}$ of data were used. If the null hypothesis of a normal distribution was rejected (at $P<.05)$, we then examined the data set for bimodality, defined as a data set in which the frequency of years falling in the middle third of the range (using the raw 


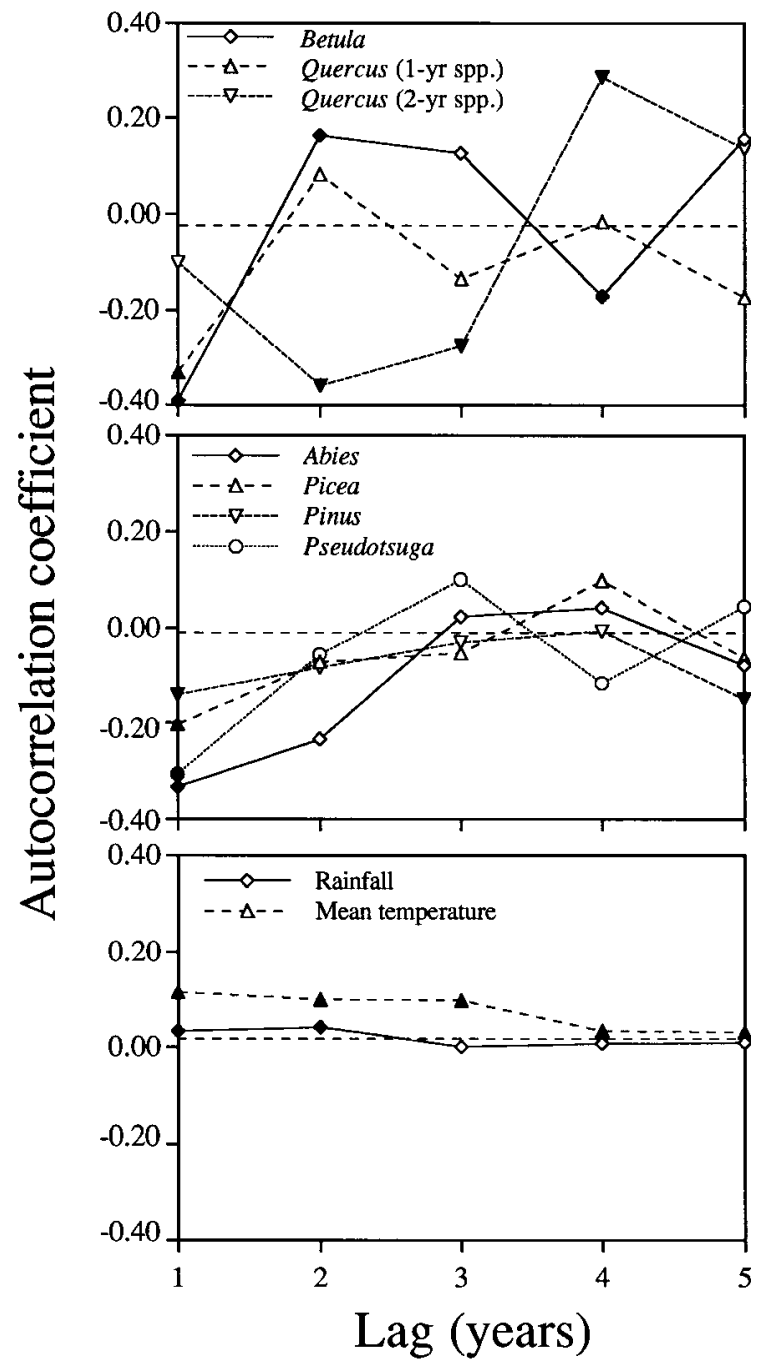

Figure 1: Temporal autocorrelations between annual seed crops of broadleafed (top), conifer genera (middle), and environmental variables (bottom) at lags of 1-5 yr; oaks (genus Quercus) are further divided into species requiring 1 and $2 \mathrm{yr}$ to mature acorns. Solid symbols are significant after sequential Bonferroni corrections within data sets using randomization tests.

or the log-transformed values) was greater than the frequency in both the upper and lower thirds of the range. Two other calculations relevant to bimodality were performed: we compared the frequency of bimodality by the above definition across all data sets to that expected by chance, and we examined the average kurtosis of individual data sets. A bimodal distribution is expected to dip in the middle (extremely platykurtic, corresponding to kurtosis $\ll 0$ ) compared to a normal distribution (Sokal and Rohlf 1981).

No single species had enough data and a sufficiently large geographic distribution to warrant separate examination by the above analyses. Thus, data sets for all species within genera were combined. Analyses were performed within genera if reasonably large samples were available; because the spatial autocorrelation analyses involved subdividing the data into categories, larger samples were generally required than for the Mantel tests. Data for oaks were divided into 1- and 2-yr species, as discussed above. In addition, we performed an among-genus comparison for the seven major genera of conifers for which we had sufficient data; genera included were Abies, Larix, Picea, Pinus, Pseudotsuga, Thuja, and Tsuga. In this latter analysis, only between-genus comparisons were made; all pairwise combinations of sites involving the same genus were excluded. Thus, the data included in the among-genera comparison of conifers did not overlap with the data used in the within-genus comparisons.

\section{Results}

\section{Temporal Autocorrelation}

For the seed production data, temporal autocorrelations were significantly negative between year $x$ and year $x+$ 1 (a lag of $1 \mathrm{yr}$ ) for all of the taxa analyzed with the exception of 2-yr species of Quercus, for which lags at 2 and $3 \mathrm{yr}$ were significantly negative (fig. 1). Several other

Table 2: Results of Mantel tests of annual seed production by Northern Hemisphere trees, annual rainfall, and mean temperature

\begin{tabular}{lcc}
\hline $\begin{array}{l}\text { Family and } \\
\text { genus }\end{array}$ & $\begin{array}{c}\text { Pairwise } \\
\text { comparisons } \\
(N)\end{array}$ & $\begin{array}{c}\text { Normalized } \\
\text { Mantel } r\end{array}$ \\
\hline Betulaceae: Betula & 591 & -.324 \\
Fagaceae: & & \\
$\quad$ Fagus & 120 & -.558 \\
$\quad$ Quercus (1-yr spp.) & 191 & -.325 \\
$\quad$ Quercus (2-yr spp.) & 178 & -.323 \\
Pinaceae: & & \\
$\quad \begin{array}{l}\text { Abies } \\
\text { Picea }\end{array}$ & 689 & -.212 \\
$\quad$ Pinus & 1,033 & -.202 \\
$\quad$ Pseudotsuga & 3,756 & -.147 \\
$\quad$ Among-genus & 56 & -.411 \\
$\quad$ comparison of & & \\
$\quad$ conifers & 13,548 & -.091 \\
Annual rainfall & 913,627 & -.177 \\
Mean summer & & \\
$\quad$ temperature & 990,408 & -.278 \\
\hline
\end{tabular}

Note: Pairwise comparisons for annual rainfall and mean summer temperature were randomly chosen from approximately $10^{7}$ (rainfall) and $5 \times 10^{6}$ (temperature) total pairwise comparisons; $P$ values are all $<.001$. 


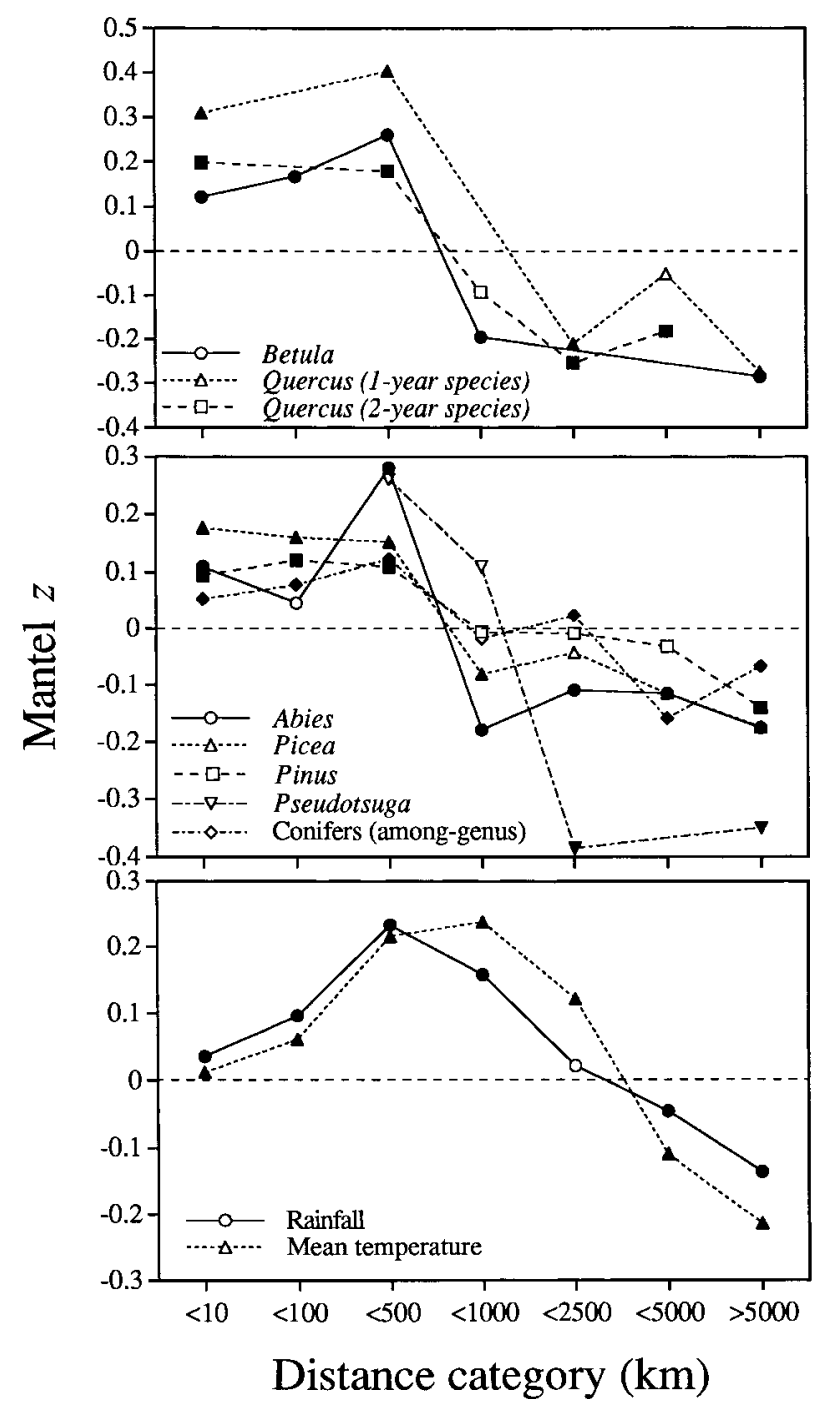

Figure 2: Mantel correlograms of the correlation between the annual seed crops of broad-leafed (top), conifer genera (middle), and environmental variables (bottom) depending on the distance between sites. Seven distance categories (listed on the $X$-axis) were used. Solid symbols are significant after sequential Bonferroni corrections within data sets using randomization tests.

significant autocorrelations also emerged but were not consistent across taxa. In contrast, temporal autocorrelations for both environmental variables were moderately, but significantly, positive for lags of 1 and $2 \mathrm{yr}$ and were mixed, but always close to 0 , at longer lag periods (fig. 1).

\section{Spatial Autocorrelation}

The Mantel tests indicated strong, significant inverse relationships between distance and the correlation between seed crops for all taxa and both environmental variables (table 2). Mantel correlograms (fig. 2) reveal modest differences between taxa and between the seed production data sets and the environmental variables, the latter of which tend to be smaller at the short-distance categories (up to $100 \mathrm{~km}$ ) and peak more strongly than most of the seed production data sets. However, all show the same general trend of positive values at short distances switching to negative values at long distances, as expected based on the Mantel tests. The majority of Mantel $z$ values are significantly different from 0 , indicating that these patterns are highly unlikely to have occurred by chance. No major

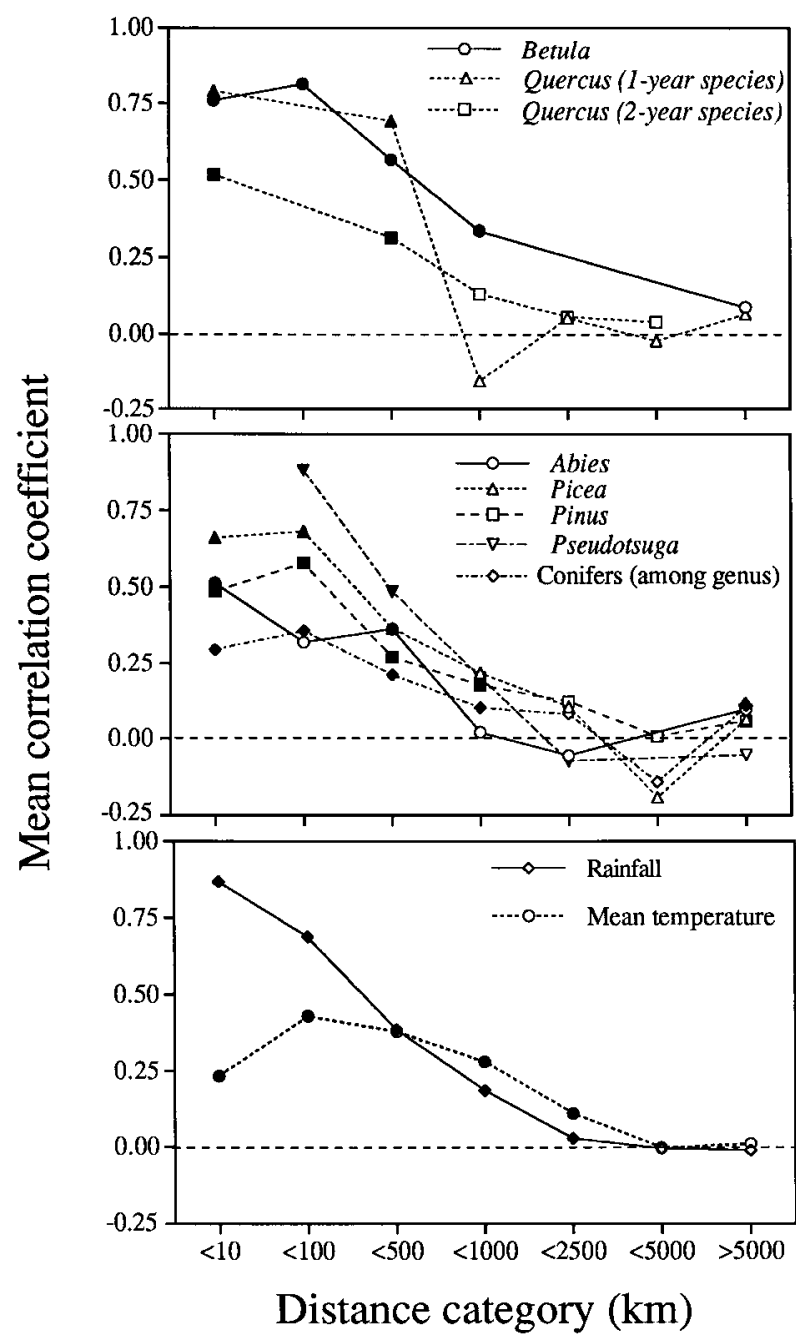

Figure 3: Modified correlograms of the correlation between the annual seed crops of broad-leafed (top), conifer genera (middle), and environmental variables (bottom) depending on the distance between sites. The conifer among-genus analysis includes cross-genera comparisons of the seven genera of conifers listed in table 1. Seven distance categories (listed on the $X$-axis) were used. Solid symbols are significant after sequential Bonferroni corrections within data sets using randomization tests. 
Table 3: Comparisons of the average distributional attributes of annual seed production by broad-leafed and conifer genera, annual rainfall, and mean summer temperature.

\begin{tabular}{|c|c|c|c|}
\hline & $\mathrm{CV}$ & Skewness & Kurtosis \\
\hline \multicolumn{4}{|l|}{ Raw data: } \\
\hline BLG & $109 \pm 37$ & $1.14 \pm .76$ & $1.03 \pm 2.66$ \\
\hline Conifers & $119 \pm 53$ & $1.37 \pm .87$ & $2.02 \pm 3.36$ \\
\hline Rainfall & $21 \pm 7$ & $.32 \pm .46$ & $.18 \pm 1.10$ \\
\hline Mean summer temperature & $\ldots$ & $.06 \pm .37$ & $.04 \pm .71$ \\
\hline \multicolumn{4}{|l|}{ Comparisons: } \\
\hline BLG versus conifers & $1.4^{\star}$ & 1.1 & 1.1 \\
\hline BLG versus rainfall & $9.0^{* * *}$ & $5.2^{* * *}$ & $2.8^{* * *}$ \\
\hline BLG versus temperature & $\ldots$ & $6.8^{* * *}$ & $3.2^{* * *}$ \\
\hline Conifers versus rainfall & $13.3^{* * *}$ & $8.9^{* * *}$ & $5.2^{* * *}$ \\
\hline Conifers versus temperature & $\ldots$ & $11.0^{\star * *}$ & $6.0^{* * *}$ \\
\hline \multicolumn{4}{|l|}{ Log-transformed data: } \\
\hline BLG & $36 \pm 30$ & $.65 \pm .73$ & $.05 \pm 2.14$ \\
\hline Conifers & $39 \pm 37$ & $.28 \pm .85$ & $-.11 \pm 2.31$ \\
\hline Rainfall & $3 \pm 1$ & $.25 \pm .45$ & $.17 \pm 1.09$ \\
\hline Mean summer temperature & $\ldots$ & $.10 \pm .40$ & $.90 \pm .89$ \\
\hline \multicolumn{4}{|l|}{ Comparisons: } \\
\hline BLG versus conifers & $1.5^{\star}$ & $2.1^{* * *}$ & .8 \\
\hline BLG versus rainfall & $9.0^{* * *}$ & $3.0^{* * *}$ & $3.7^{* * *}$ \\
\hline BLG versus temperature & $\ldots$ & $4.1^{* * *}$ & $3.9^{* * *}$ \\
\hline Conifers versus rainfall & $13.5^{* * *}$ & $1.9^{* * *}$ & $5.6^{* * *}$ \\
\hline Conifers versus temperature & $\ldots$ & $3.3^{* * *}$ & $5.8^{* * *}$ \\
\hline
\end{tabular}

Note: Listed are mean $( \pm \mathrm{SD})$ coefficients of variation $(\mathrm{CV})$, skewness, and kurtosis for data sets providing at least $6 \mathrm{yr}$ of information. Comparisons are by Kolmogorov-Smirnov two-sample tests $(Z$ value listed). $B L G=$ broad-leafed genera; $N$ data sets $=86$ (broad-leafed genera), 205 (conifers), 4,701 (rainfall), and 3,225 (mean summer temperature).

${ }^{*} P<.05$.

${ }^{* * *} P<.001$

differences among taxa or between seed production and the environmental variables stand out; the strong negative values at the larger distance categories for Pseudotsuga are in part most likely due to the absence of sufficient data for analysis in several of the distance categories for this genus.

Results from modified correlograms (fig. 3) are also similar across taxa. In general, mean correlation coefficients are significantly $>0$ for most distance categories up to $500 \mathrm{~km}$ for all taxa and up to $1,000 \mathrm{~km}$ for Betula and Pinus. However, there was a small but significant level of synchrony in the among-genus comparison of conifers at the largest $(>5,000 \mathrm{~km})$ spatial scale.

\section{Distributional Characteristics}

Distributions of annual seed production for broad-leafed and coniferous trees were generally similar or marginally different, with the sole exception of greater skewness among the broad-leafed trees using log-transformed data (table 3). In contrast, all 20 comparisons of $\mathrm{CV}$, skewness,

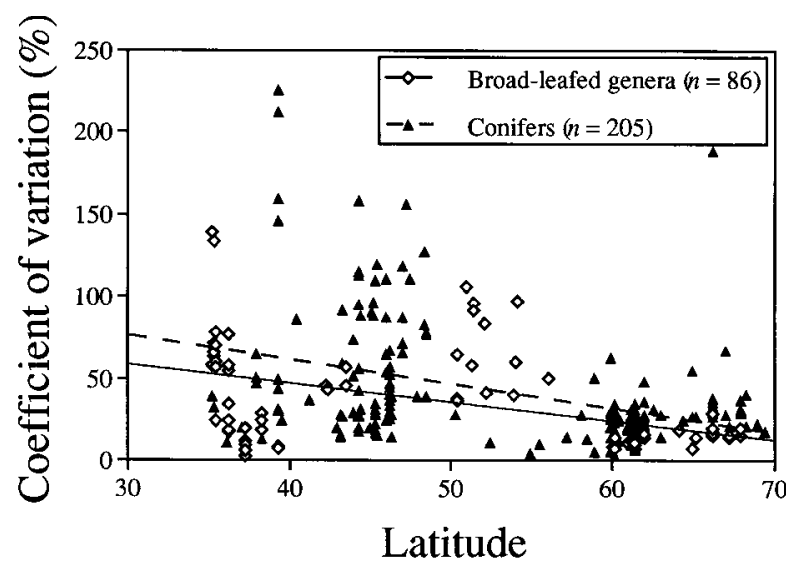

Figure 4: Latitudinal gradient in coefficient of variation of annual seed production by broad-leafed and conifer genera using log-transformed values. Only interval and ratio-level data sets with at least $6 \mathrm{yr}$ of data were used; genera included are listed in table 1 . Both correlations are significant (see "Distributional Characteristics"). 


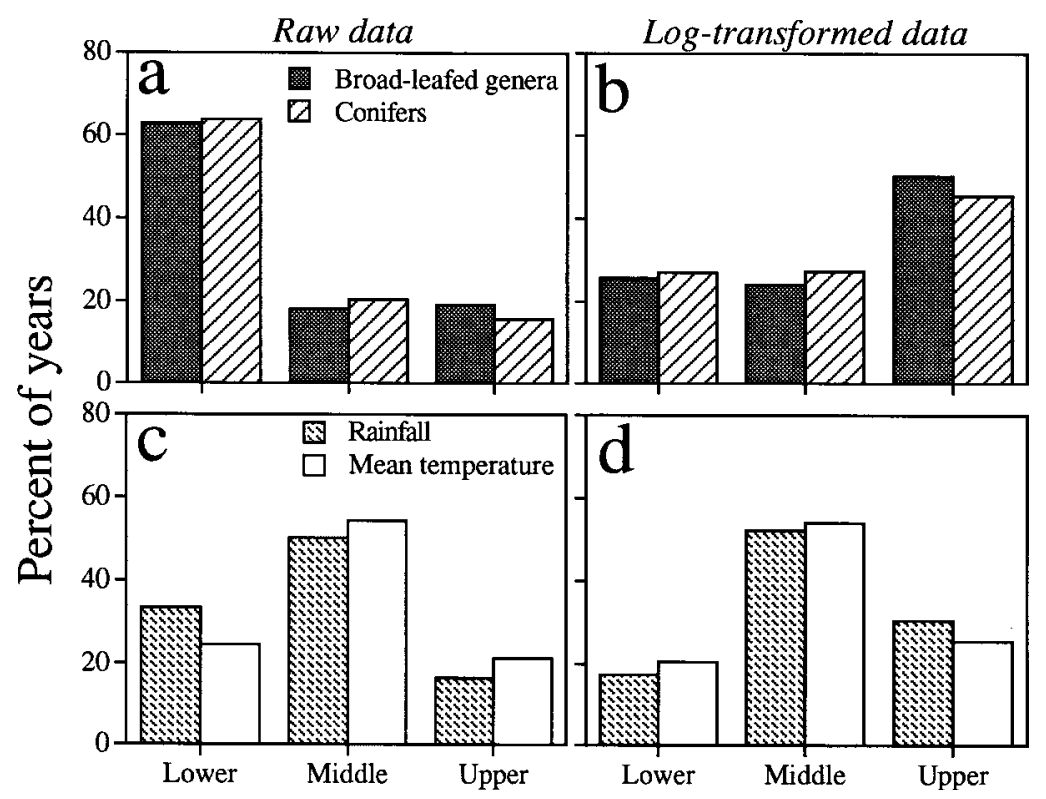

Figure 5: Proportion of years seed production (top, panels $a$ and $b$ ) and environmental variables (bottom, panels $c$ and $d$ ) fell into the lower, middle, and upper thirds of the their overall ranges using the raw (left side, panels $a$ and $c$ ) and log-transformed (right side, panels $b$ and $d$ ) data. For seed production, only interval and ratio-level data were used. Number of years: 921 (broad-leafed genera), 2,457 (conifers), 265,150 (annual rainfall), and 205,883 (mean summer temperature).

and kurtosis were highly significantly different between both types of trees and both environmental variables (table $3)$.

The CVs in seed production were not correlated with latitude using the raw data (broad-leafed genera: $r_{\mathrm{s}}=$ $-0.13, n=86, P=.23$; conifers: $r_{\mathrm{s}}=0.00, n=205$, NS), but declined significantly with latitude using the logtransformed data (broad-leafed genera: $r_{\mathrm{s}}=-0.51, n=$ 86, $P<.001$; conifers: $r_{\mathrm{s}}=-0.27, n=205, P<.001$; fig. 4). This latitudinal gradient matched that of annual rainfall, CVs for which also declined significantly with latitude (raw values: $r_{\mathrm{s}}=-0.30, n=4,701, P<.001$; logtransformed values: $\left.r_{\mathrm{s}}=-0.23, n=4,701, \quad P<.001\right)$. These relationships are all unchanged in more complex analyses controlling for number of years within data sets.

The first step we used to investigate bimodality was to test individual data sets for normality using KolmogorovSmirnov one-sample tests. The results (table 4) indicate that for all data sets, the null hypothesis of normality could be rejected for only one $(1.2 \%)$ of the broad-leafed genera and $16(7.8 \%)$ of the conifers. Of these significantly nonnormal data sets, nine were bimodal by the minimal criterion that the frequency of years in the middle third of the distribution of annual seed crop size was greater than the frequency of years in both the upper and lower thirds. This proportion is not significantly greater than expected by chance $\left(\chi_{1}^{2}=2.9\right.$, NS). Using the individual data sets, regardless of whether normality could be rejected or not, 36 of $86(41.9 \%)$ of broad-leafed genera data sets (32 [37.2\%] using the log-transformed data) and 81 of 205 (39.5\%) of conifer data sets $(80$ [39.0\%] using the logtransformed data) were bimodal. None of these values are significantly different from the number expected by chance (four comparisons; all $\chi_{1}^{2}<3.5$, all $P>.05$ ).

When data sets were combined, half of the genera were bimodal (table 4). Overall, broad-leafed genera, but not conifers, exhibited slight bimodality with both the raw and log-transformed data (fig. 5).

For the environmental variables, normality could be rejected for only a small proportion of data sets (table 4). Looking at the individual data sets, regardless of whether normality could be rejected or not, 164 of 4,701 (3.5\%) of rainfall data sets (146 [3.1\%] using the log-transformed data) and 47 of 3,225 (1.5\%) of mean summer temperature data sets (39 [1.2\%] using the log-transformed data) were bimodal. In all cases, these are significantly less than the number expected by chance (four comparisons; all $\chi_{1}^{2}>$ 999, all $P<.001)$. Combining data sets, the middle third of the distributions for both rainfall and mean summer temperatures contained slightly over half the years, contrasting markedly with the distributions of annual seed production (fig. 5).

Lastly, average kurtosis was positive, indicating a slight but nonsignificant tendency toward leptokurtosis, for all 
Table 4: Summary of one-sample Kolmogorov-Smirnov tests for normality on the individual (left side) and combined (right side) data sets using the raw and (except for mean summer temperature) logtransformed data

\begin{tabular}{|c|c|c|c|c|c|c|}
\hline \multirow[b]{2}{*}{ Family and genus } & \multicolumn{3}{|c|}{ Individual data sets } & \multicolumn{3}{|c|}{ Combined data sets } \\
\hline & Raw & $\begin{array}{l}\text { Log- } \\
\text { transformed }\end{array}$ & $N$ & Raw & $\begin{array}{l}\text { Log- } \\
\text { transformed }\end{array}$ & Years $(N)$ \\
\hline \multicolumn{7}{|l|}{ Seed production: } \\
\hline Betulaceae: Betula & 0 & 0 & 30 & Yes & No & 334 \\
\hline \multicolumn{7}{|l|}{ Fagaceae: } \\
\hline Fagus & 0 & 6.3 & 16 & Yes & Yes & 171 \\
\hline Quercus & 2.5 & 0 & 40 & No & No & 416 \\
\hline \multicolumn{7}{|l|}{ Pinaceae: } \\
\hline Abies & 13.3 & 6.7 & 30 & Yes & Yes & 248 \\
\hline Larix & 0 & 0 & 9 & No & No & 94 \\
\hline Picea & 17.8 & 11.1 & 45 & No & No & 688 \\
\hline Pinus & 1.9 & 2.9 & 105 & No & No & 1,261 \\
\hline Pseudotsuga & 40.0 & 0 & 5 & No & Yes & 80 \\
\hline Tsuga & 0 & 0 & 8 & Yes & Yes & 54 \\
\hline Thuja & 0 & 0 & 3 & Yes & Yes & 32 \\
\hline Broad-leaved genera combined & 1.2 & 0 & 86 & Yes & Yes & 921 \\
\hline Conifers combined & 7.8 & 4.9 & 205 & No & No & 2,457 \\
\hline \multicolumn{7}{|l|}{ Environmental variables: } \\
\hline Rainfall & .2 & .1 & 4,701 & No & No & 265,150 \\
\hline Mean summer temperature & .2 & .2 & 3,225 & No & No & 205,883 \\
\hline
\end{tabular}

Note: For seed production, only data sets presenting interval or ratio-level data with at least 6 yr of information are included. Values listed are percentage of data sets that are significantly $(P<.05)$ nonnormal.

the data sets except that for the log-transformed seed production of conifers, which was very slightly, and again nonsignificantly, negative (table 3). Leptokurtic distributions are more peaked than expected based on a normal distribution, in contrast to a bimodal distribution, which should be extremely platykurtic.

\section{Discussion}

Significantly negative temporal autocorrelation at a lag of $1 \mathrm{yr}$ was found for all taxa with the exception of Quercus species that require $2 \mathrm{yr}$ to mature acorns, for which a matching, 2-yr lag was detected (fig. 1; why a significant 1 -yr correlation was found for Pinus species that also generally require 2 or even $3 \mathrm{yr}$ to mature seeds is unknown; Preston 1965). Several significant autocorrelations at longer lag periods were detected as well, indicating that seed crops in a particular year may significantly affect subsequent reproductive effort. These patterns were not reflected in either annual rainfall or mean summer temperature (fig. 1) and thus support the hypothesis that trees deplete their nutritional resources when they produce large seed crops as predicted by the evolved strategy but not the resource-tracking hypothesis.

With respect to spatial autocorrelation, patterns in seed production and environmental variables are generally sim- ilar, with both exhibiting large-scale spatial synchrony generally declining with distance (table 2; fig. 3 ) or, when analyzed with Mantel correlograms, peaking at intermediate spatial scales (fig. 2). Thus, spatial autocorrelation patterns are consistent with the environmental tracking hypothesis. However, they are also consistent with the evolved strategy hypothesis, since both hypotheses predict that environmental cues are likely to synchronize growth and reproduction.

Distributional patterns of seed production matched those of the environmental factors in a few ways, such as the rarity of bimodality (table 4 ) and the inverse latitudinal gradient (fig. 4), but not in many others, including the distributions of CVs, skewness, kurtosis (table 3 ) and overall tendency toward bimodality (fig. 5). Thus, in several key ways these results reject the hypothesis that annual seed production patterns match the distribution of either annual rainfall or mean summer temperatures.

In combination with the switching between growth and reproduction documented by Koenig and Knops (1998a), as well as prior work on particular systems (Norton and Kelly 1988; Sork et al. 1993; Kelly 1994; Tapper 1996), these results support the hypothesis that annual seed production by forest trees is generally an evolved strategy. Although seed production is often likely to be correlated with environmental factors in either case, temporal au- 
tocorrelation and patterns of variability do not strongly match those exhibited by either annual rainfall or mean temperature, two environmental factors likely to correlate with available resources in a given year.

The relevance of these results to several other issues is worth mentioning. First, the latitudinal gradient in relative variability of annual seed production (fig. 4) suggests that the degree of mast-fruiting as indexed by the CV (Kelly 1994) may be more widespread in tropical taxa than currently known. This possibility was suggested by Sork (1993) and is consistent with the extensive mast fruiting found in Malaysian dipterocarps (Janzen 1974; Ashton et al. 1988).

Second, our results do not support the hypothesis that seed production by most populations of trees exhibit "strict" masting whereby distributions are unambiguously bimodal. High variability in annual seed output, patterns of temporal autocorrelation, a general failure to achieve strong bimodality, and detectable trade-offs between growth and reproduction at large taxonomic and geographic scales are all consistent with the hypothesis that genera of most major Northern hemisphere trees are "normal" masters sensu Kelly (1994). Such partial masting matches the results of Herrera et al. (1998) but contradicts the pattern predicted by recent theoretical studies of mast reproduction (Yamauchi 1996) and presents a challenge to future efforts to model this phenomenon. In contrast to Herrera et al. (1998), however, we do not advocate abandoning the terms "masting" and "mast fruiting," which we feel serve the useful purpose of focusing attention on an evolutionarily significant and biologically interesting phenomenon, even if it is not as distinct or well defined as may have been originally envisioned.

Third, the large geographic scale on which seed production patterns are often synchronized, both within and between genera, has important implications for wildlife populations dependent on the seeds of forest trees for food. In general, resident populations of birds and mammals dependent on mast are likely to be affected synchronously over large geographic areas by both bumper crops providing abundant food and, perhaps even more dramatically, by crop failures. Given recent work in eastern U.S. deciduous forests documenting effects of variable acorn crops at several levels within the community (Ostfeld et al. 1996; Jones et al. 1998), it is likely that the geographical patterns of annual seed production by forest trees have far-reaching effects on ecosystem function and biodiversity that have only begun to be explored.

Unanswered by these analyses is the functional significance of mast fruiting; that is, to what ecological factor(s) is mast fruiting an adaptation? Synchrony of seed production over large geographic and taxonomic scales facilitates predator satiation (Silvertown 1980) of mobile predators, but the lack of strong bimodality in most of the data sets does not. Wind pollination (Smith et al. 1990) leading to a higher percentage of fertilization in high flowering years remains a strong alternative. Complicating this issue is the fact that seeds of most tree species suffer predation from a range of species, both invertebrate and vertebrate, and that at least some of the latter are simultaneously important as dispersal agents. Determining the relative importance of these and other hypotheses potentially favoring mast fruiting (Kelly 1994) is yet to be accomplished.

\section{Acknowledgments}

We thank D. Kelly, D. Meeter, D. Schemske, C. Smith (who suggested adding the weather analyses), J. Travis, and two anonymous reviewers for comments. Thanks also to M. Heino, E. Ranta, and the Spatial Ecology Program of the Division of Population Ecology, University of Helsinki, where the senior author was hosted while working on the article. Financial support for this work was provided by the University of California's Integrated Hardwood Range Management Program and the National Science Foundation.

\section{Literature Cited}

Ashton, P. S., T. J. Givnish, and S. Appanah. 1988. Staggered flowering in the Dipterocarpaceae: new insights into floral induction and the evolution of mast fruiting in the aseasonal Tropics. American Naturalist 132: 44-66.

Bock, C. E., and L. W. Lepthien. 1976. Synchronous eruptions of boreal seed-eating birds. American Naturalist 110:559-571.

Büsgen, M., and E. Münch. 1929. The structure and life of forest trees. Chapman \& Hall, New York.

Fortin, M.-J., and J. Gurevitch. 1993. Mantel tests: spatial structure in field experiments. Pages 342-359 in S. M. Scheiner and J. Gurevitch, eds. Design and analysis of ecological experiments. Chapman \& Hall, New York.

Hannon, S. J., R. L. Mumme, W. D. Koenig, S. Spon, and F. A. Pitelka. 1987. Acorn crop failure, dominance, and a decline in numbers in the cooperatively breeding acorn woodpecker. Journal of Animal Ecology 56: 197-207.

Herrera, C. M., P. Jordano, J. Guitián, and A. Traveset. 1998. Annual variability in seed production by woody plants and the masting concept: reassessment of principles and relationship to pollination and seed dispersal. American Naturalist 152:576-594.

Janzen, D. H. 1974. Tropical blackwater rivers, animals, and mast fruiting by the Depterocarpaceae. Biotropica 6:69-103. 
Jones, C. G., R. S. Ostfeld, M. P. Richard, E. M. Schauber, and J. O. Wolff. 1998. Chain reactions linking acorns to gypsy moth outbreaks and Lyme disease risk. Science (Washington, D.C.) 279:1023-1026.

Kelly, D. 1994. The evolutionary ecology of mast seeding. Trends in Ecology \& Evolution 9:465-470.

Koenig, W. D. 1999. Spatial autocorrelation in ecological studies. Trends in Ecology \& Evolution 14:22-26.

Koenig, W. D., and J. M. H. Knops. 1998a. Scale of mastseeding and tree-ring growth. Nature (London) 396: 225-226.

$1998 b$. Testing for spatial autocorrelation in ecological studies. Ecography 21:423-429.

Koenig, W. D., R. L. Mumme, W. J. Carmen, and M. T. Stanback. 1994. Acorn production by oaks in central coastal California: variation within and among years. Ecology 75:99-109.

Koenig, W. D., J. M. H. Knops, W. J. Carmen, M. T. Stanback, and R. L. Mumme. 1996. Acorn production by oaks in central coastal California: influence of weather at three levels. Canadian Journal of Forest Research 26:1677-1683.

Legendre, P., and M.-J. Fortin. 1989. Spatial pattern and ecological analysis. Vegetatio 80:107-138.

Norton, D.A., and D. Kelly. 1988. Mast seeding over 33 years by Dacrydium cupressinum Lamb. (rimu) (Podocarpaceae) in New Zealand: the importance of economies of scale. Functional Ecology 2:399-408.

Oden, N. L. 1984. Assessing the significance of a spatial correlogram. Geographical Analysis 16:1-16.

Oden, N. L., and R. R. Sokal. 1986. Directional autocorrelation: an extension of spatial correlograms to two dimensions. Systematic Zoology 35:608-617.
Ostfeld, R. S., C. G. Jones, and J. O. Wolff. 1996. Of mice and mast. BioScience 46:323-329.

Preston, R. J., Jr. 1965. North American trees. MIT Press, Cambridge, Mass.

Royama, T. 1992. Analytical population dynamics. Chapman \& Hall, New York.

Silvertown, J. W. 1980. The evolutionary ecology of mast seeding in trees. Biological Journal of the Linnean Society $14: 235-250$.

Smith, C. C., J. L. Manrick, and C. L. Kramer. 1990. The advantage of mast years for wind pollination. American Naturalist 136:154-166.

Sokal, R. R., and F. J. Rohlf. 1981. Biometry. W. H. Freeman, San Francisco.

Sork, V. L. 1993. Evolutionary ecology of mast-seeding in temperate and tropical oaks (Quercus spp.). Vegetatio 107/108:133-147.

Sork, V. L., J. Bramble, and O. Sexton. 1993. Ecology of mast-fruiting in three species of North American deciduous oaks. Ecology 74:528-541.

Tapper, P.-G. 1996. Long-term patterns of mast fruiting in Fraxinus excelsior. Ecology 77:2567-2572.

Wallis, W. A., and H. B. Roberts. 1956. Statistics. Free Press, New York.

Woodward, A., D. G. Silsbee, E. G. Schreiner, and J. E. Means. 1994. Influence of climate on radial growth and cone production in subalpine fir (Abies lasiocarpa) and mountain hemlock (Tsuga mertensiana). Canadian Journal of Forest Research 24:1133-1143.

Yamauchi, A. 1996. Theory of mast reproduction in plants: storage-size dependent strategy. Evolution 50: 1795-1807. 